\begin{tabular}{|c|c|}
\hline Title & $\begin{array}{l}\text { Mechanism of Orographic Precipitation around the Meghal ay a Plateau A ssociated with Intraseasonal O scillation and } \\
\text { the Diurnal Cycle }\end{array}$ \\
\hline Author(s) & Sato, Tomonori \\
\hline Citation & $\begin{array}{l}\text { Monthly Weather Review, 141(7), 2451-2466 } \\
\text { https://doi.org/10.1175MWR-D-12-00321.1 }\end{array}$ \\
\hline Issue Date & $2013-07$ \\
\hline Doc URL & http:/hdl.handle.net/2115/53972 \\
\hline Rights & (C) Copyright 2013 A merican Meteorological Society (A MS). \\
\hline Type & article \\
\hline File Information & mwr-TSato2013_2451.pdf \\
\hline
\end{tabular}

Instructions for use 


\title{
Mechanism of Orographic Precipitation around the Meghalaya Plateau Associated with Intraseasonal Oscillation and the Diurnal Cycle
}

\author{
TOMONORI SATO \\ Faculty of Environmental Earth Science, Hokkaido University, Sapporo, Japan
}

(Manuscript received 2 November 2012, in final form 6 January 2013)

\begin{abstract}
Mesoscale processes that cause tremendous amounts of precipitation around the Meghalaya Plateau, northeast India, were investigated using a regional atmospheric model, with a particular focus on the possible role of an intraseasonal oscillation (ISO) and the diurnal cycle. A numerical experiment was conducted using the Weather Research and Forecasting Model (WRF) to simulate a prominent submonthly-scale ISO event observed during June-July 2004. A WRF experiment successfully simulated the timing and magnitude of precipitation during the first active period and subsequent inactive period of the ISO, despite large biases in the second active period. The WRF experiment revealed that the magnitude of prevailing southwesterly winds in the lower troposphere differs significantly between active and inactive periods; strong southwesterly flow transports abundant moisture to the southern slope of the Meghalaya Plateau during the active period, which triggers forced lifting and brings orographic precipitation. However, low-level wind during the inactive period is too weak to overcome the vertical stratification barrier; hence, it is unable to reach the condensation level. The WRF experiment suggested that the diurnal cycle of precipitation is enhanced during the active period, exhibiting an evening to early morning maximum, as observed by the Tropical Rainfall Measuring Mission (TRMM). The experiment also indicated a prominent nocturnal low-level jet (LLJ) appearing at $900 \mathrm{hPa}$. The direction of the LLJ varies clockwise with time, which accelerates the preexisting southwesterly flow during 1800-0600 LT. The diurnal variation of the LLJ is responsible for the evening to early morning maximum of precipitation, thus contributing to the precipitation variability in the ISO.
\end{abstract}

\section{Introduction}

A tremendous amount of precipitation falls in South and Southeast Asia. The diabatic heat released as a form of water condensation heating is essential to sustain the ascending branch of the Hadley circulation. The record for the highest annual precipitation on the earth (26 $461 \mathrm{~mm}$ ) was observed at Cherrapunjee (see Fig. 1 for location; $25.25^{\circ} \mathrm{N}, 91.73^{\circ} \mathrm{E}$ ), India, from August 1860 to July 1861; the next highest precipitation values were recorded over the surrounding areas in South Asia. Cherrapunjee is located to the south of the Meghalaya Plateau (Fig. 1), near the boundary between India and Bangladesh. The elevation of the plateau is typically lower than $2000 \mathrm{~m}$, which is not particularly high compared to the Himalayas to the north. Despite this relatively low

Corresponding author address: Tomonori Sato, Faculty of Environmental Earth Science, Hokkaido University, Kita-10, Nishi-5, Sapporo, 060-0810, Japan.

E-mail: t_sato@ees.hokudai.ac.jp elevation, interaction between the plateau's topography and southerly flows from the Indian summer monsoon is thought to be a primary cause of heavy precipitation in this region.

In low-latitude regions, intraseasonal oscillations (ISOs) are a dominant atmospheric variability mode; therefore, they have been the targets of many studies. In particular, a 30-60-day ISO referred to as the MaddenJulian oscillation (MJO; Madden and Julian 1972) has been studied intensively to understand its impacts on low- and midlatitude atmospheric variability (e.g., Sardeshmukh and Hoskins 1988; Hendon and Salby 1994; Berbery and Nogués-Paegle 1993) because lowfrequency atmospheric variations such as ISOs are expected to have the potential to extend the lead time of medium-range weather forecasts (e.g., Wheeler and Weickmann 2001; Waliser et al. 2003; Miura et al. 2007). In addition to the 30-60-day ISO, a high-frequency ISO is involved in the summer monsoon variability around South and Southeast Asia (e.g., Krishnamurti and Bhalme 1976; Murakami 1976; Yasunari 1979). Ohsawa 


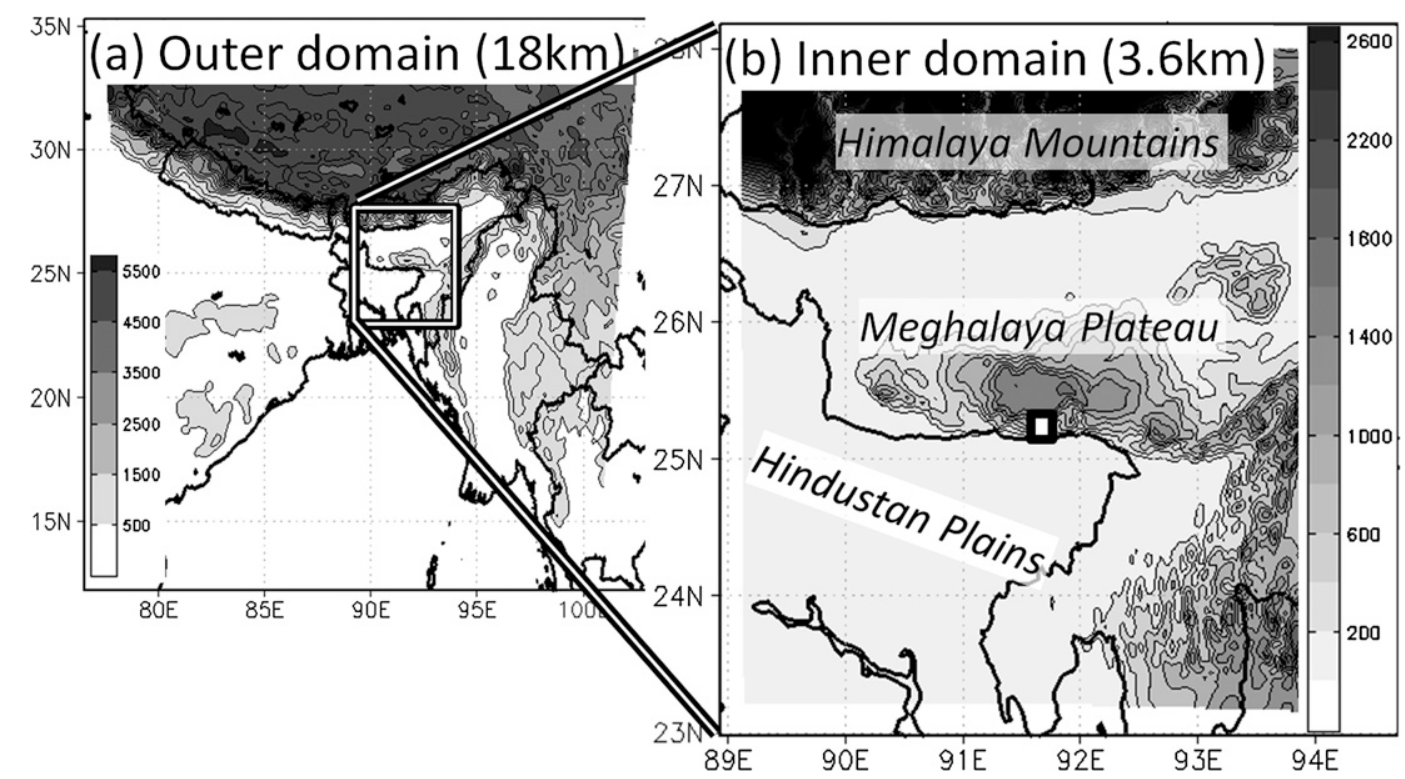

FIG. 1. Topography (m) around the study area for the (a) outer domain and (b) inner domain. A small square in (b) indicates the location of Cherrapunjee station.

et al. (2000) later demonstrated a prominent precipitation variation with a 7-25-day frequency in Bangladesh. Recently, Fujinami et al. (2011) found that the precipitation spectrum in Bangladesh exhibited a pronounced peak for about a 14-day period, while a peak for a 30-40-day period was not statistically significant. In addition, the submonthly scale (7-25 day) precipitation variance was significantly larger than the 30-60-day variance, suggesting that the submonthly-scale ISO exerted a greater influence than the 30-60-day ISO on the interannual variation of June-August mean precipitation (Fujinami et al. 2011). Because Bangladesh is situated in the vicinity of the Meghalaya Plateau, it is highly probable that the submonthly-scale ISO plays an important role in the presence of heavy precipitation around the plateau. Few observational studies have been conducted previously of the mesoscale circulations during the active phase of the submonthly ISO. Ohsawa et al. (2000) analyzed radiosonde observations at Dhaka, Bangladesh $\left(90.38^{\circ} \mathrm{N}, 23.76^{\circ} \mathrm{E}\right)$, and found that the southwesterly wind in the lower troposphere rotates clockwise with increasing altitude. Fujinami et al. (2011) investigated the three-dimensional structure of the circulation using a reanalysis dataset, showing that the westerly wind in the lower troposphere covers the Meghalaya Plateau during the active phase. However, the role of ISO-related mesoscale circulation and topography in the heavy precipitation around the Meghalaya Plateau remains unclear.

The diurnal cycle is also an important feature of precipitation variability in the Asian monsoon region and has been studied by data analysis (e.g., Barros et al. 2000; Ohsawa et al. 2001; Nesbitt and Zipser 2003; Mori et al. 2004; Hirose and Nakamura 2005; Sato et al. 2007; Zhou et al. 2008; Huang et al. 2010; Xu and Zipser 2011) and numerical modeling (e.g., Yang and Slingo 2001; Arakawa and Kitoh 2005; Kataoka and Satomura 2005; Oouchi et al. 2009; Sato et al. 2009). A geostationary satellite data analysis demonstrated that the precipitation around the Meghalaya Plateau exhibits a midnight peak at approximately from 0000 to 0600 local time (LT; UTC $+6 \mathrm{~h}$ ), which is obviously different to that observed in surrounding areas (Ohsawa et al. 2001). The earlier Tropical Rainfall Measuring Mission (TRMM) Precipitation Radar (PR) analysis also suggested maximum activity of precipitating convective systems during 0000-0600 LT (Romatschke and Houze 2011). Studies have shown that the southward-propagating precipitation systems over the Bay of Bengal (Webster et al. 2002) and Bangladesh (Kataoka and Satomura 2005) also possess diurnal periodicity. However, few studies have addressed the behavior of the diurnal cycle in association with the ISO in this region. It is necessary to clarify the possible effects of the diurnal cycle during the active phase of the ISO on heavy precipitation around the Meghalaya Plateau.

Recently, regional atmospheric models have been applied widely in the study of mesoscale processes in various regions of the world. An important advantage of using regional models is their potential to simulate orographically induced convective systems (e.g., Wang et al. 2004; Sato and Xue 2013). Therefore, a regional 

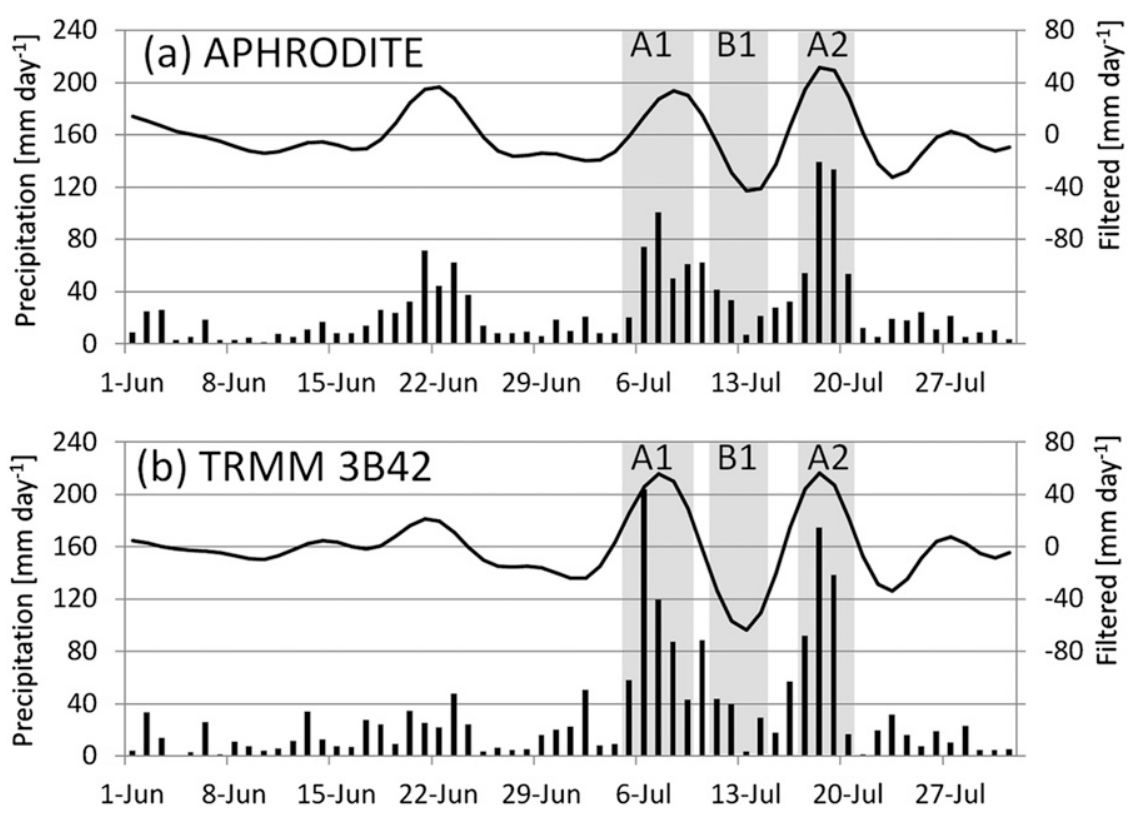

FIG. 2. Time series of precipitation in (a) APHRODITE and (b) TRMM 3B42 around the Meghalaya Plateau $\left(24^{\circ}-26^{\circ} \mathrm{N}, 90^{\circ}-92^{\circ} \mathrm{E}\right)$. The $7-25$-day filtered precipitation is shown with solid line. A1 (5-9 Jul) and A2 (17-20 Jul) indicate the active periods and B1 (11-15 Jul) indicates the break period.

model experiment driven by reanalysis data is a suitable approach to investigate mesoscale atmospheric circulation under a controlling large-scale forcing such as that controlled by an ISO. The purpose of this study is, first, to demonstrate a regional atmospheric model experiment that captures much of precipitation variability around the Meghalaya Plateau including the submonthlyscale ISO and the diurnal cycle. Then, the mesoscale circulation that characterizes active and inactive periods of the submonthly-scale ISO is investigated to understand the mechanisms of orographic precipitation around the Meghalaya Plateau.

\section{Description of submonthly ISO of summer 2004}

It is important to conduct a long-term high-resolution numerical experiment for understanding mesoscale features in relation to the ISO. For example, with such an experiment for many different years, we would be able to analyze statistical characteristics of the mesoscale circulations. However, the computation costs required to conduct such an experiment are considerable. Therefore, as a first step, this study focuses on June and July of 2004 as a target period to study mesoscale features during the submonthly-scale ISO. In summer 2004, a prominent submonthly-scale ISO was observed by a rain gauge at Cherrapunjee (Murata et al. 2008). Figure 2 illustrates precipitation time series averaged over $24^{\circ}-26^{\circ} \mathrm{N}, 90^{\circ}-92^{\circ} \mathrm{E}$, covering the Meghalaya Plateau, using the Asian Precipitation Highly Resolved Observational Data Integration Towards Evaluation of Water Resources (APHRODITE; Yatagai et al. 2009, 2012) and TRMM 3B42 dataset. To include as many rain gauges as possible incorporated in APHRODITE, the averaging area contains a part of the Hindustan Plains. APHRODITE is a daily precipitation product on a $0.25^{\circ} \times 0.25^{\circ}$ mesh grid based on a dense rain gauge network with orographic effects taken into account during interpolation (Yatagai et al. 2012). Since the number of available rain gauges is limited around the Meghalaya Plateau, the spatial mean precipitation presented in Fig. 2a largely reflects four gauge stations (also see Fig. 7 for locations of the gauges) and the climatology precipitation pattern (Yatagai et al. 2012). Figure 2b illustrates the precipitation time series based on TRMM 3B42 (hereafter 3B42) observations on a $0.25^{\circ} \times 0.25^{\circ}$ mesh grid, estimated using TRMM's microwave channel data and infrared data from geostationary satellites. Lines in Fig. 2 represent 7-25-day filtered time series for the two datasets. There are several precipitation peaks in the filtered daily precipitation time series of the APHRODITE and 3B42 products. In APHRODITE, a first peak occurs around 21 June, with more than $70 \mathrm{~mm}$ day $^{-1}$, followed by a weak precipitation period until 4 July. A second peak appears from 7 to 11 July, with maximum values of more than $100 \mathrm{~mm} \mathrm{day}^{-1}$. 

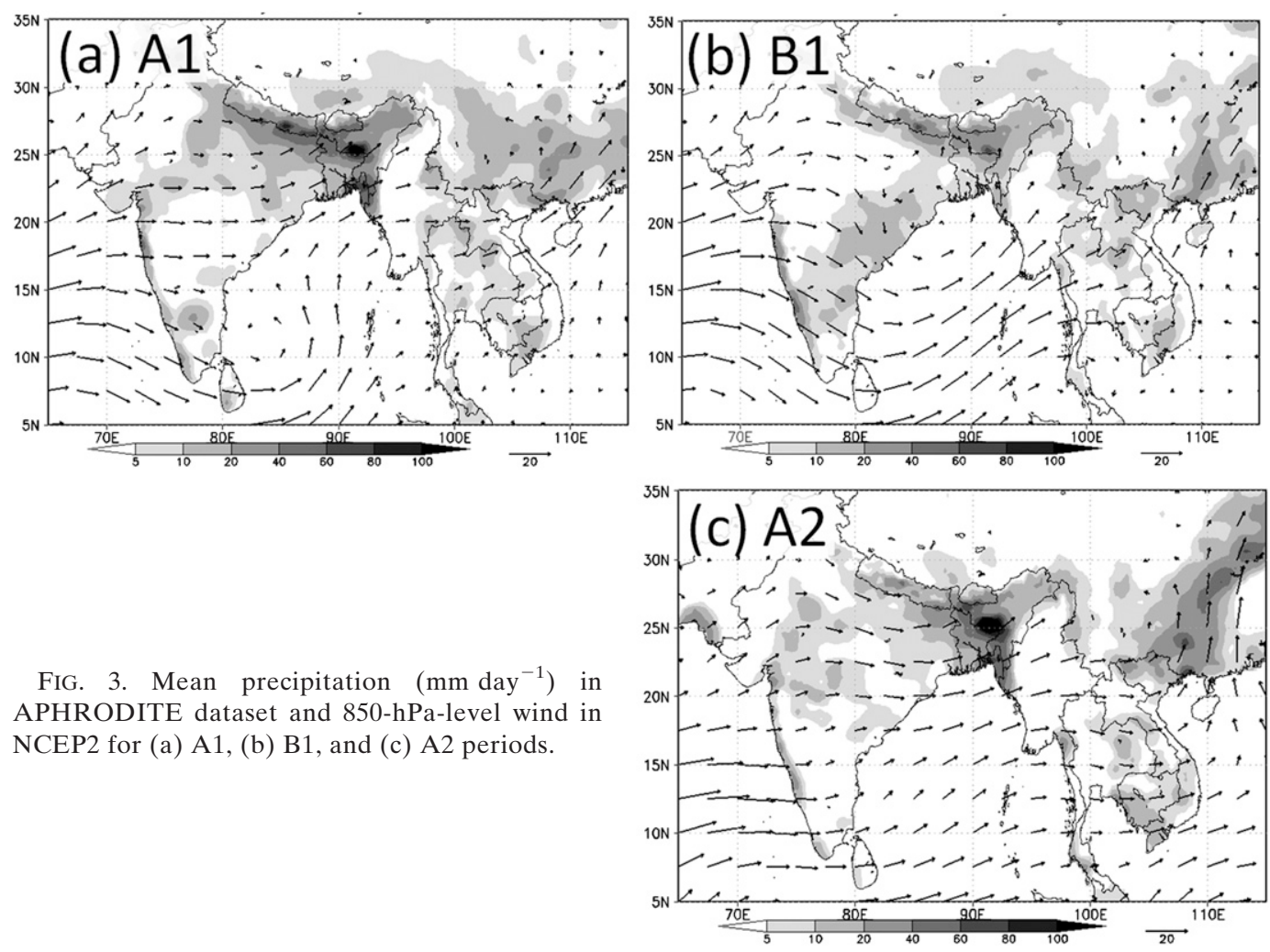

FIG. 3. Mean precipitation $\left(\mathrm{mm} \mathrm{day}^{-1}\right)$ in APHRODITE dataset and 850-hPa-level wind in NCEP2 for (a) A1, (b) B1, and (c) A2 periods.

A third peak occurs from 18 to 19 July and exhibits the highest precipitation for the whole of summer 2004. The timing of the precipitation peaks in APHRODITE is very similar to that by gauge-based sounding at Cherrapunjee (Murata et al. 2008). The precipitation from 3B42 exhibits a weak peak in late June and another two pronounced peaks in July, which agrees roughly with the APHRODITE. However, the first peak is smaller and second peak is much stronger than that in APHRODITE. This discrepancy probably results from differences between the algorithms used in the precipitation products, as described by Yatagai et al. (2012). Despite the differences in absolute values, the two datasets are consistent with respect to the timing of active and inactive precipitation during July 2004. Here we define two active periods, A1 (5-9 July) and A2 (17-20 July), and an inactive period, B1 (11-15 July), as shown in Fig. 2. These periods correspond to dates when either of the filtered precipitation data exceeds one standard deviation, calculated for the filtered time series during June-July 2004; the standard deviations are 20.8 and $24.5 \mathrm{~mm} \mathrm{day}{ }^{-1}$ for APHRODITE and 3B42, respectively. The temporal variations of area-averaged precipitation are very similar to the in situ measurement at the Cherrapunjee (Murata et al. 2008), which suggests the area-averaged precipitation in Fig. 2 well represents the time series of precipitation at the Meghalaya Plateau. Since the 3B42-derived precipitation in late June was rather small, this study focuses mainly on July.

Figure 3 depicts a mean precipitation distribution and 850-hPa-level wind in the National Centers for Environmental Prediction-U.S. Department of Energy (NCEP-DOE) Reanalysis 2 data (NCEP2; Kanamitsu et al. 2002) averaged over the A1, B1, and A2 periods. During the A1 period, heavy precipitation is located around the Meghalaya Plateau and along the Himalayas (Fig. 3a). Low-level winds are predominantly westerly and southwesterly around the Meghalaya region from the Indian continent and Bay of Bengal. Likewise, marked precipitation is located around the Meghalaya Plateau during the A2 period, together with strong westerly flow in the lower troposphere (Fig. 3c). In contrast, low-level wind is very weak around the Meghalaya Plateau during the B1 period, in association with cyclonic circulation over the northwestern Bay of Bengal that weakens the low-level westerly flow. The difference in lower-tropospheric circulation between active and inactive periods suggests that the westerly/ southwesterly wind toward the Meghalaya Plateau plays an important role in the heavy precipitation anchored on the Meghalaya Plateau. This agrees with a previous study by Fujinami et al. (2011), which analyzed 20 years 


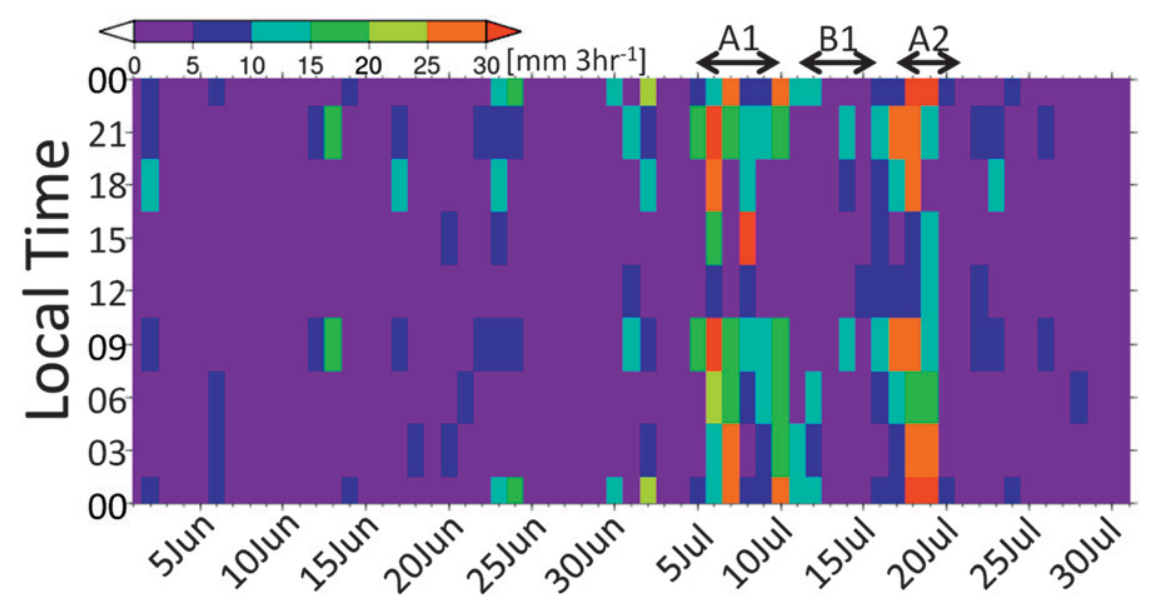

FIG. 4. Date and time section of TRMM 3B42 precipitation around the Meghalaya Plateau $\left(24^{\circ}-26^{\circ} \mathrm{N}, 90^{\circ}-92^{\circ} \mathrm{E}\right)$.

of reanalysis data and identified the anomalous circulation related to a 7-25-day ISO. Therefore, precipitation features from July 2004 represent synoptic-scale circulation features similar to the typical submonthlyscale ISO and are suitable for investigation of mesoscale processes by means of a dynamical downscaling approach.

To examine the diurnal cycle of convective activity, Fig. 4 illustrates day-by-day variation of the diurnal cycle of precipitation around the Meghalaya Plateau. A pronounced diurnal cycle appears during the $\mathrm{A} 1$ and $\mathrm{A} 2$ periods but is very weak during June and the B1 period. The diurnal cycle during A1 and A2 exhibits a mature phase from evening until the morning hours, which is in agreement with the satellite observations shown in Ohsawa et al. (2001), who showed a midnight maximum of convective activity over northern Bangladesh using blackbody temperature obtained from a geostationary satellite.

\section{Model and numerical experiment}

A regional atmospheric model, the Advanced Research Weather Research and Forecasting Model (ARW-WRF), version 3.2.1 (Skamarock et al. 2008), is adopted in this study. Horizontal mesh size is $3.6 \mathrm{~km}$ $(151 \times 151$ grids $)$, centered around the Meghalaya Plateau, two-way nested within an 18 -km $(133 \times 133$ grids $)$ mesh grid domain that covers $14^{\circ}-34^{\circ} \mathrm{N}, 78^{\circ}-102^{\circ} \mathrm{E}$ (Fig. 1). The elevation near the plateau center is higher than $1500 \mathrm{~m}$ in the $3.6-\mathrm{km}$ mesh domain, whereas the topography in the $18-\mathrm{km}$ mesh domain is rather smoothed. Model topography for the nested domain shows that the $3.6-\mathrm{km}$ mesh is sufficient to capture the detailed features of the Meghalaya Plateau. The vertical grid number is 40 layers. Physics parameterizations adopted are the cumulus convection scheme (Kain 2004), cloud microphysics scheme (Hong et al. 2004), shortwave radiation scheme (Dudhia 1989), longwave radiation scheme (Rapid Radiative Transfer Model; Mlawer et al. 1997), planetary boundary layer scheme (the 2.5 level of Nakanishi and Niino 2004, 2006), and the Noah land surface model (Chen and Dudhia 2001). One may anticipate that the domain size (Fig. 1a) could be too small. A northern lateral boundary located over high mountains, such as the Tibetan Plateau, sometimes generates computational errors. However, another experiment with a larger domain size, which contained the whole Tibetan Plateau, failed to simulate realistic timing and structure of the ISO, as will be mentioned in the following section. This is probably because of the overheating and erroneous convection that was unrealistically generated in the model (not shown), which eventually destroyed realistic atmospheric fields. Such defects were improved upon by using a smaller domain size. The sensitivity of the simulated circulations to the domain size is consistent with the earlier studies, which clarified the higher downscaling skills as reducing a domain size (Leduc and Laprise 2009). Therefore, this study uses a small domain to preserve the realistic large-scale circulation patterns that are required to characterize the ISO phase.

WRF is driven using atmospheric forcing data obtained from NCEP2. The four outermost rows of the grid points from the lateral boundary are nudged to the forcing dataset. The weekly mean optimum interpolation sea surface temperature (OISST; Reynolds et al. 2002) is given as an ocean surface boundary condition. The simulation was initiated on 15 June 2004 and terminated on 25 July 2004. 


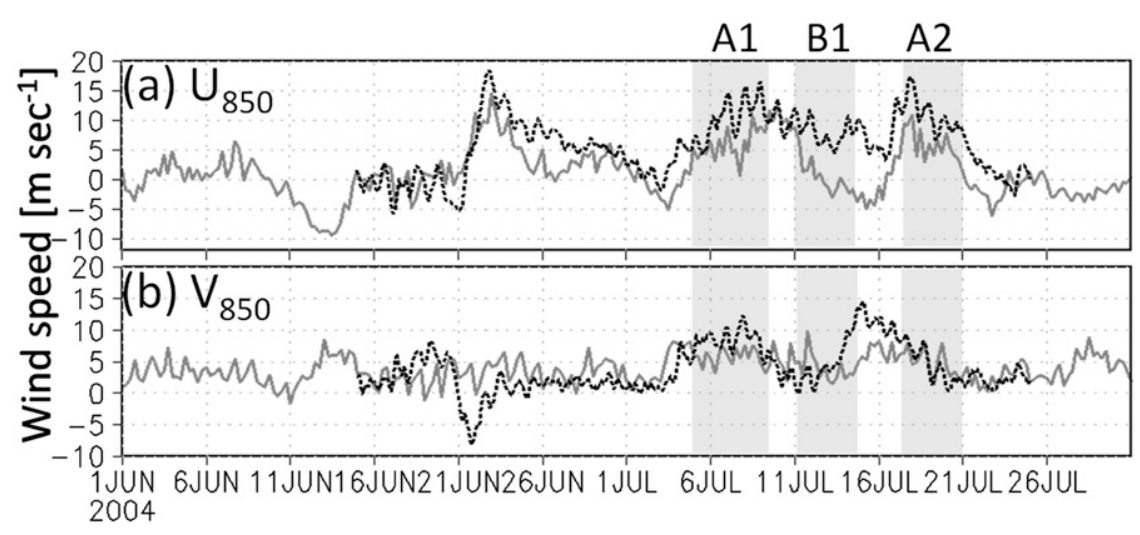

FIG. 5. Time series of (a) zonal and (b) meridional wind speed at $850 \mathrm{hPa}$ over the Meghalaya Plateau $\left(24^{\circ}-26^{\circ} \mathrm{N}, 90^{\circ}-92^{\circ} \mathrm{E}\right)$. The solid gray line and the broken line indicate NCEP2 reanalysis and WRF experiment (outer domain), respectively.

\section{Results}

\section{a. Low-level wind}

Figure 5 illustrates the time series of 850 -hPa-level wind speed around the Meghalaya Plateau. Zonal wind speed becomes greater than $10 \mathrm{~m} \mathrm{~s}^{-1}$ during A1 and A2 in the WRF experiment, which roughly follows the NCEP2 time series. During B1, zonal wind in NCEP2 is markedly weaker than in the active periods and shows weak easterly flow reflecting a cyclonic circulation (Fig. 3b). Although WRF simulates a weakening of zonal wind during $\mathrm{B} 1$, its wind speed is much stronger than that in NCEP2.

The 850-hPa meridional wind around the Meghalaya Plateau shows very similar temporal variation in NCEP2 and WRF (Fig. 5). The southerly wind increases a few days prior to the precipitation peak during A1 and A2. A large difference between NCEP2 and WRF is present during 14-16 July, corresponding to the latter part of B1; simultaneously, WRF shows southerly wind that is too strong. During B1, both the zonal and meridional components of the 850-hPa-level wind indicate large biases in the WRF experiment. In addition, zonal wind in NCEP2 exhibits a lag of 1 day compared to that of WRF, which is obvious during the onset of A1 and A2. For example, the zonal wind increased on 4 July in NCEP2 but on 3 July in WRF (Fig. 5a). Both the bias and time lag in the zonal wind variation are consistent with the errors in simulated precipitation that will be addressed in the following section.

\section{b. Precipitation}

Figure 6 illustrates the precipitation time series around the Meghalaya Plateau in WRF. WRF successfully simulates heavy precipitation in early July and the following break period in mid-July. The heavy precipitation corresponding to A1 starts on 3 July in WRF, which is earlier than the observed onset (5 July). The precipitation maximum during $\mathrm{A} 1$ is $140 \mathrm{~mm} \mathrm{day}^{-1}$, which is between the values derived from APHRODITE and 3B42. The break of daily precipitation is clearly identified in mid-July. However, the timing and

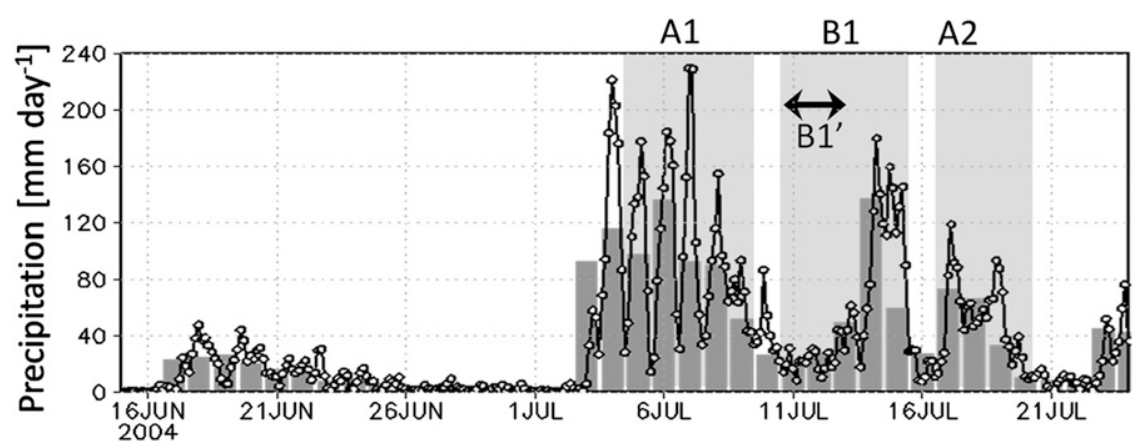

FIG. 6. Time series of precipitation $\left(\mathrm{mm} \mathrm{day}^{-1}\right)$ simulated in WRF experiment around the Meghalaya Plateau $\left(24^{\circ}-26^{\circ} \mathrm{N}, 90^{\circ}-92^{\circ} \mathrm{E}\right)$. The daily mean (bar) and 3-h mean (line) values are plotted together. 
magnitude of precipitation in late July differ from those observed. In the earlier part of B1 (11-13 July), simulated precipitation was very low. Meanwhile, WRF overestimates precipitation in the later part of B1 (14-15 July). The simulated precipitation indicates a peak corresponding to A2, although the amount of rainfall is approximately half of that observed.

The earlier onset of precipitation for A1 in WRF is consistent with the earlier shift in zonal wind variation at $850 \mathrm{hPa}$. The large bias in $850-\mathrm{hPa}$ zonal and meridional wind during B1 (Fig. 5) is also consistent with WRF's overestimation of precipitation during the latter part of the B1 period. These results suggest that the performance of the regional model in simulating ISO-related precipitation around the Meghalaya Plateau is very sensitive to the quality of the large-scale circulation. Furthermore, the model biases in large-scale circulation result in considerable differences in the amount of precipitation.

A dominant diurnal cycle in simulated precipitation appears during the A1 period, which is in good agreement with 3B42 observations (Fig. 4), whereas the presence of the diurnal cycle is ambiguous during the $\mathrm{B} 1$ and A2 periods (Fig. 6). Although the diurnal cycle seems to be active during days with high daily precipitation in B1 and A2, its amplitude is much smaller than that seen in A1. We will discuss the relationship between low-level winds and the diurnal cycle of precipitation in section 5 .

Spatial distribution of total precipitation is compared for the APHRODITE, 3B42, and WRF experiments for the A1, B1, and A2 periods (Fig. 7). In APHRODITE's figure, grid boxes that contain rain gauge(s) are overlaid to identify the location of the most reliable value. During A1, the APHRODITE and 3B42 depict most precipitation over the southern slope of the Meghalaya Plateau (241 and $235 \mathrm{~mm} \mathrm{day}^{-1}$ for grid values, respectively). 3B42 tends to overestimate the precipitation over the Hindustan Plain. WRF reproduces observed precipitation centers along the southern slopes; however, precipitation is overestimated compared to the observations $\left(685 \mathrm{~mm} \mathrm{day}{ }^{-1}\right)$. Strong northeastward moisture transport toward the Meghalaya is obvious in the lower troposphere. To the northeast of the Meghalaya Plateau, both observations and WRF show very small precipitation, suggesting reduced precipitation as a result of the rain shadow effect on the lee side of the plateau. WRF successfully simulates the small precipitation over the Hindustan Plain. During A2, observed precipitation patterns are very similar to those in A1. Meanwhile, the WRF precipitation again shows overestimation over the mountains: maximum precipitation values over the Meghalaya Plateau are 284, 262, and $368 \mathrm{~mm} \mathrm{day}^{-1}$ for APHRODITE, 3B42, and WRF, respectively. Although the total precipitation in WRF is lower than that during A1, it is still higher than observations. The moisture flux again shows northeastward moisture transport in the lower layer. Although there is uncertainty in spaceborne precipitation estimates over a region without ground truth, the results indicate that the WRF obviously overestimates precipitation near the mountains. The precipitation patterns during B1 seem different between the two observation products. APHRODITE shows maximum precipitation along the Himalayas but 3B42 does not. Simulated precipitation for B1 is overestimated compared to the observations, despite the amount being smaller than that for the two active periods. The 900-hPa-level moisture flux tends to exhibit a northward direction. As we have confirmed in Fig. 6, precipitation in the latter part of B1 is overestimated in WRF. To compare precipitation patterns during a break period, mean precipitation patterns during 11-13 July (indicated as B1' in Fig. 6) are also compared. The simulated precipitation for $\mathrm{B}^{\prime}$ is obviously smaller than that for B1, with weaker northward moisture flux. The horizontal extent of the area experiencing precipitation is rather limited, which agrees with observations.

To examine the vertical structure of simulated precipitation during the active period of the 7-25-day ISO, a vertical cross section of the convective system is analyzed. Figure 8a displays a snapshot of cloud pattern at 1100 LT 6 July using an infrared $(10.8 \mu \mathrm{m})$ channel obtained from the Visible and Infrared Scanner (VIRS) and near-surface rainfall rate measured by the PR sensor on board TRMM. Orographic precipitation of more than $30 \mathrm{~mm} \mathrm{~h}^{-1}$ is found over the Meghalaya Plateau in the PR image, showing heavy precipitation on the plateau and very weak precipitation in the surrounding areas. The vertical cross section along the $\mathrm{A}-\mathrm{A}^{\prime}$ line indicates that convective clouds are widely distributed over the Meghalaya Plateau and southern slopes. The maximum rainfall rate, higher than $48 \mathrm{~mm} \mathrm{~h}^{-1}$, appears over the southern slope. The rainfall rate exhibits maximum values at $1-5 \mathrm{~km}$, and the mean top height of convective cells is approximately $7-8 \mathrm{~km}$. Another snapshot for 0600 LT 17 July, corresponding to the A2 period, shows distinct orographic enhancement in near-surface rainfall (Fig. 8b). In spite of the low brightness temperature near the foot of the plateau, heavy precipitation was present only over the Meghalaya Plateau. The surface rainfall on the southern slope exceeds $80 \mathrm{~mm} \mathrm{~h}^{-1}$, suggesting a very strong rainfall event around Cherrapunjee. The vertical cross section indicates high convective systems developed over the southern slope, with the cloud top reaching $14-\mathrm{km}$ altitude. The spatial 


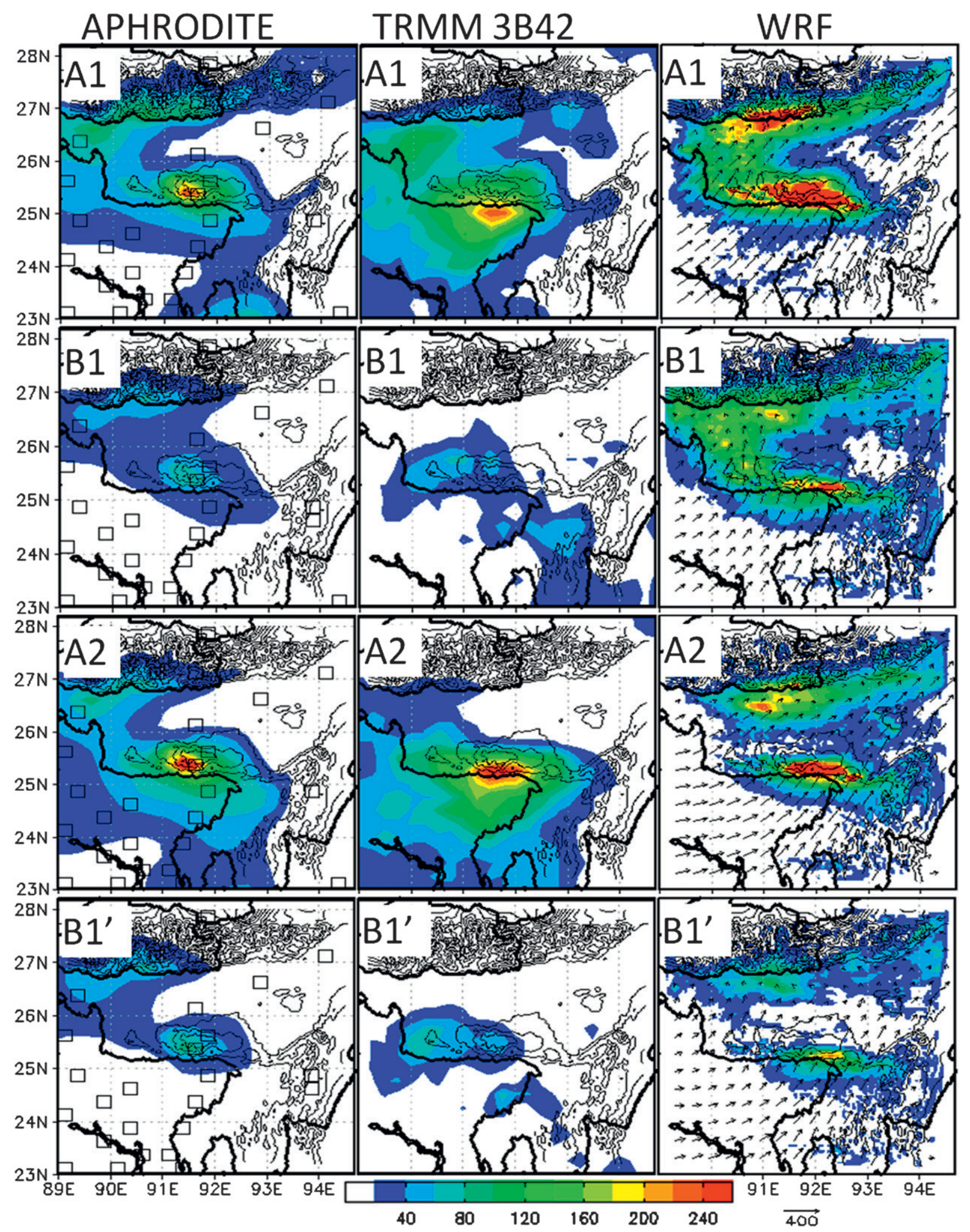

FIG. 7. Total precipitation during A1, B1, A2, and B1' periods $\left(\mathrm{mm} \mathrm{day}^{-1}\right.$ ). Data sources are (left) APHRODITE, (middle) TRMM 3B42, and (right) the WRF results. Grid boxes with rain gauge(s) are shown with solid square symbols in APHRODITE's figures. Vectors in WRF result indicate moisture flux at the 900-hPa level $\left(\mathrm{g} \mathrm{m} \mathrm{kg}^{-1} \mathrm{~s}^{-1}\right)$. 

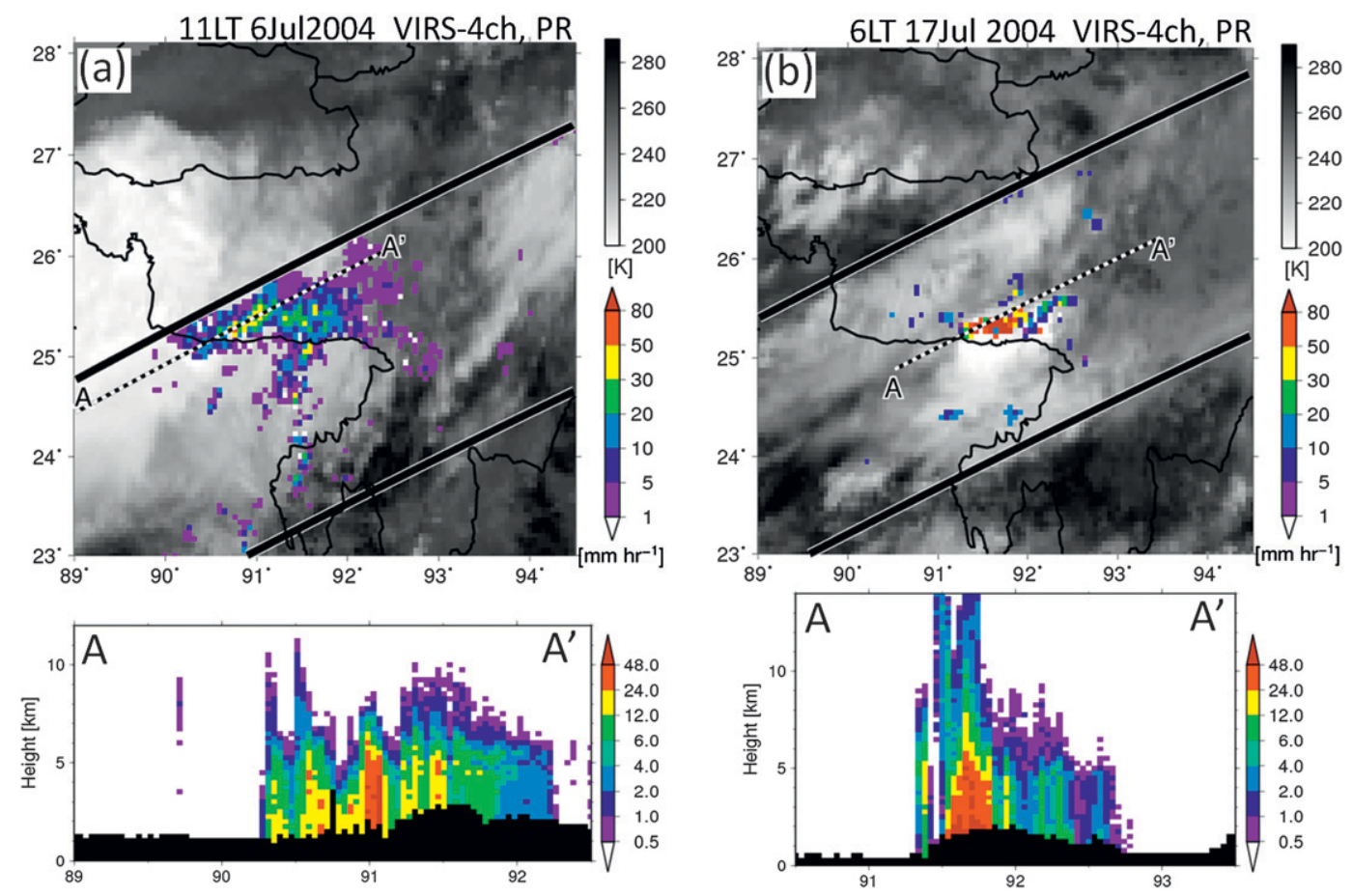

FIG. 8. Near-surface rainfall rate $\left(\mathrm{mm} \mathrm{h}^{-1}\right)$ and brightness temperature $(\mathrm{K})$ observed by TRMM sensors on (a) 6 and (b) $17 \mathrm{Jul}$. (bottom) Vertical cross sections of rainfall rate $\left(\mathrm{mm} \mathrm{h}^{-1}\right)$ along the $\mathrm{A}-\mathrm{A}^{\prime}$ line are shown. The thick solid line indicates the range of the TRMM PR observations. The black shading in the cross section indicates surface clutter.

distribution of precipitation in the case of 17 July is narrower than that observed on 6 July. The simulated precipitation and mesoscale circulation corresponding to the date of the TRMM snapshot is shown in Fig. 9. Although it is difficult to evaluate a long-term mesoscale simulation on the basis of a snapshot for a typical event, simulated convective systems possess similar structures to those observed by TRMM PR. In both cases, WRF produces orographic enhancement of precipitation around the Meghalaya Plateau. Northeastward moisture transport is strong at the $900-\mathrm{hPa}$ level, suggesting that the stronger southwesterly wind with abundant moisture brings orographic precipitation along the Meghalaya Plateau than the climatology condition. A vertical cross section shows that surface precipitation is centered near the top of the mountain and that the mixing ratio of the condensed water has a maximum value around the 500-hPa level for both days. The horizontal distribution of condensed water on 6 July was spread widely over the lee side of mountain, while on 17 July the cumulus convection was isolated on the upwind side of the slope; these features are consistent with properties observed by TRMM PR (Fig. 8). The WRF experiment also suggests the importance of low-level wind for convective precipitation. Vertical structures of southwesterly wind in the two snapshots show stronger horizontal wind in the lower troposphere. In particular, southwesterly wind reaches a maximum value, stronger than $15 \mathrm{~m} \mathrm{~s}^{-1}$, below $800 \mathrm{hPa}$, suggesting a low-level jet (LLJ) structure.

In this section, the WRF simulation is evaluated using reanalysis data, satellite, and rain gauge-based surface precipitation products, and the vertical structure of convective systems from TRMM PR. WRF successfully simulates the temporal variation of low-level winds except for biases in the B1 period and an earlier shift prior to the $\mathrm{A} 1$ and $\mathrm{A} 2$ periods. The precipitation time series agrees roughly with observations. However, precipitation amounts over the mountains are poorly simulated. The vertical structure indicates a feature of orographically induced precipitation that is in good agreement with TRMM observations. In the following section, the relationship between the simulated diurnal cycle of precipitation and mesoscale circulation will be addressed using the WRF results.

\section{Diurnal cycle and mesoscale circulation}

As inferred from 3B42 (Fig. 4) and the WRF simulation (Fig. 6), the diurnal cycle of precipitation is distinct during the active phase of the submonthly ISO. In this 
(a) 12LT 6Jul 2004
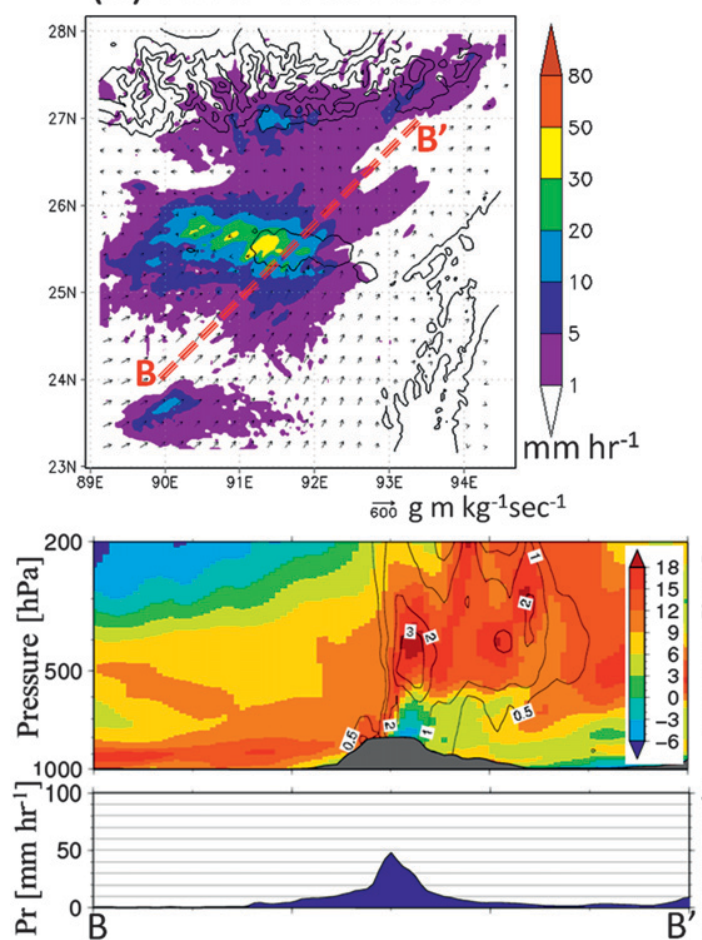

(b) 6LT 17Jul 2004
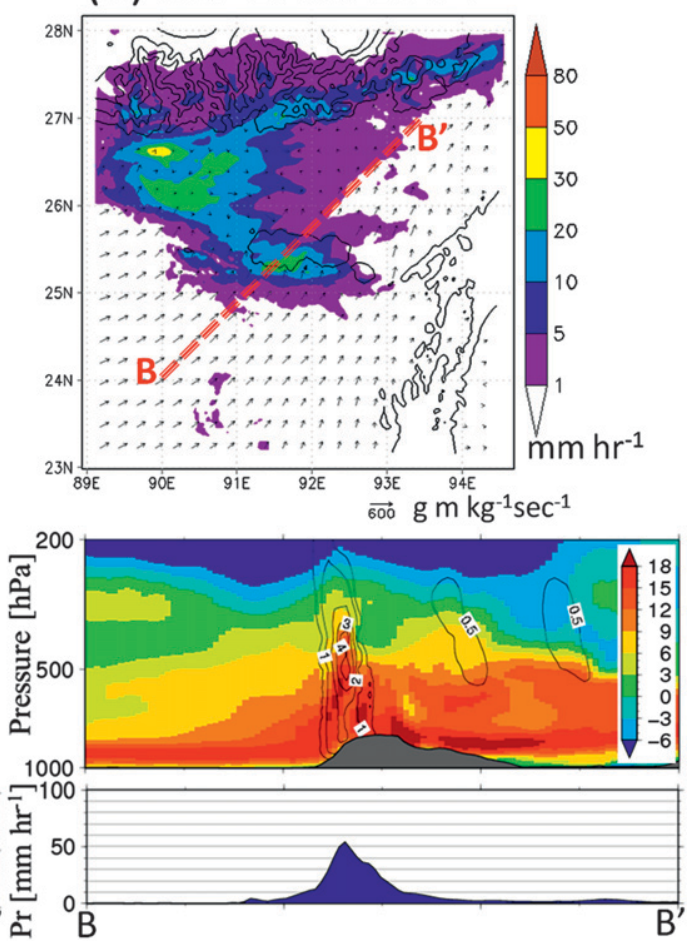

FIG. 9. Distributions of precipitation $\left(\mathrm{mm} \mathrm{h}^{-1}\right)$ and 900 -hPa-level moisture flux $\left(\mathrm{g} \mathrm{m} \mathrm{kg}^{-1} \mathrm{~s}^{-1}\right)$ in the WRF experiment at (a) $1200 \mathrm{LT} 6 \mathrm{Jul}$ and (b) $0600 \mathrm{LT} 17 \mathrm{Jul}$. (bottom) Cross section of horizontal wind speed (shaded; $\mathrm{m} \mathrm{s}^{-1}$ ), mixing ratio of hydrometeors (contour; $\left.\mathrm{g} \mathrm{kg}^{-1}\right)$, and precipitation $\left(\mathrm{mm} \mathrm{h}^{-1}\right)$ along the $\mathrm{B}-\mathrm{B}^{\prime}$ line.

section, the relationship between the diurnal cycle of precipitation and mesoscale circulations is investigated to clarify the mechanism responsible for orographic precipitation around the Meghalaya Plateau. Figure 10 shows precipitation patterns and vertical cross sections across the Meghalaya Plateau from 1800 LT 6 July to 1500 LT 7 July during A1. The convective system that was shown in Fig. 9 has moved to the eastern part of the plateau and weakened by 1800 LT 6 July (Fig. 10a). The low-level southwesterly is weak over the Hindustan Plain. The vertical cross section also shows a weakened LLJ relative to that at $1200 \mathrm{LT}$ (Fig. 9). At $2100 \mathrm{LT}$, southwesterly winds start increasing over the plain. The vertical distribution of the wind speed clearly shows that the LLJ develops around the 900-hPa level (Fig. 10b). The LLJ is further intensified at 0000 LT 7 July, eventually reaching the southern slope of the Meghalaya Plateau (Fig. 10c). At the northern tip of the jet, strong southwesterly winds climb the slope and initiate upward motion (not shown) in addition to the cloud condensation. The LLJ is dominant over the plain from 0000 to 0600 LT (Figs. 10c-e), which agrees well with the time of heavy precipitation over the plateau. The top of the convective system indicated by the high liquid water content reaches $200 \mathrm{hPa}$. The LLJ reaches a mature state at $0600 \mathrm{LT}$ and, simultaneously, the strongest convection occurs over the plateau. The LLJ and convective precipitation begin to weaken at $0900 \mathrm{LT}$ (Fig. $10 \mathrm{f})$, and the orographic precipitation becomes weak as the LLJ structure diminishes at 1200 and 1500 LT (Figs. $10 \mathrm{~g}, \mathrm{~h})$. These results from the WRF experiment strongly suggest that the diurnal cycle of the LLJ plays a crucial role in regulating the diurnal cycle of precipitation over the Meghalaya Plateau. Since the diurnal cycle of precipitation tends to be pronounced during the active phase of the submonthly ISO, the nocturnal LLJ is also an important process for ISO-related precipitation. Moreover, the WRF experiment suggests that the elevation of the Meghalaya Plateau is sufficient to initiate forced lifting along the southern slope because the LLJ developed around the 900-hPa level.

Figure 11 illustrates the diurnal variation of the 900-hPa-level wind during 6-7 July corresponding to A1. The vectors represent the anomaly from 2-day mean wind (i.e., from the southwest during this period as shown in Fig. 9). The southwesterly wind to the south of the Meghalaya Plateau increases overnight, especially from 0000 to 0600 LT. Conversely, the southwesterly 

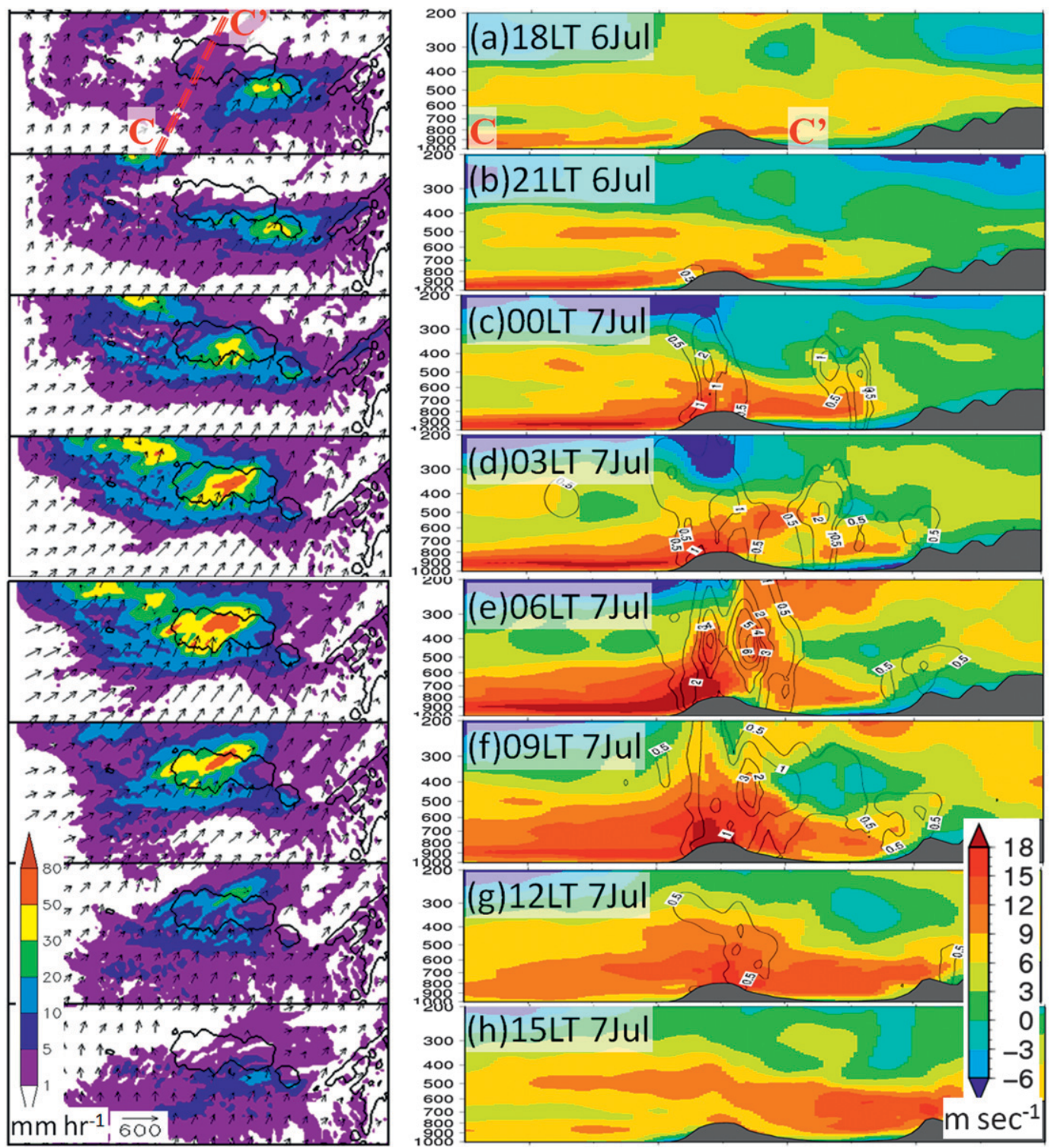

FIG. 10. (left) Precipitation ( $\mathrm{mm} \mathrm{h}^{-1}$ ) and 900-hPa-level moisture flux ( $\mathrm{g} \mathrm{m} \mathrm{kg}^{-1} \mathrm{~s}^{-1}$ ) from $1800 \mathrm{LT} 6 \mathrm{Jul}$ to 1500 LT 7 Jul. (right) Vertical cross section for wind speed (shaded; $\mathrm{m} \mathrm{s}^{-1}$ ) and mixing ratio of hydrometeors (contour; $\mathrm{g} \mathrm{kg}^{-1}$ ) along the $\mathrm{C}-\mathrm{C}^{\prime}$ line.

wind decreases in the afternoon hours of 1200-1800 LT. It is interesting that the anomalous wind direction turns clockwise with time over the plain regions, especially to the southwest of the Meghalaya Plateau where the topography is nearly flat. Terao et al. (2006) and Murata et al. (2008) discovered a similar clockwise rotation of low-level wind using radiosonde observations at Dhaka $\left(23.76^{\circ} \mathrm{N}, 90.38^{\circ} \mathrm{E}\right)$. They also pointed out that the vertical profile of wind vectors exhibited the Ekman spiral structure, in which the wind direction rotates clockwise with increasing altitude. The WRF results in this study also display a similar profile (not shown). It is evident from Figs. 10 and 11 that the nocturnal LLJ is distributed widely over the eastern part of the Hindustan Plain. The development of the nocturnal LLJ is likely induced by atmospheric boundary layer processes over the plain. The LLJ in this study develops at approximately $900 \mathrm{hPa}$ after the evening hours. The level of maximum wind speed corresponds to the height where the nighttime stable layer first establishes after the deformation of the daytime mixed layer. Then, the wind speed in the LLJ begins to increase after the upper planetary boundary layer is released from surface friction. The nocturnal LLJ can develop even during inactive periods, 


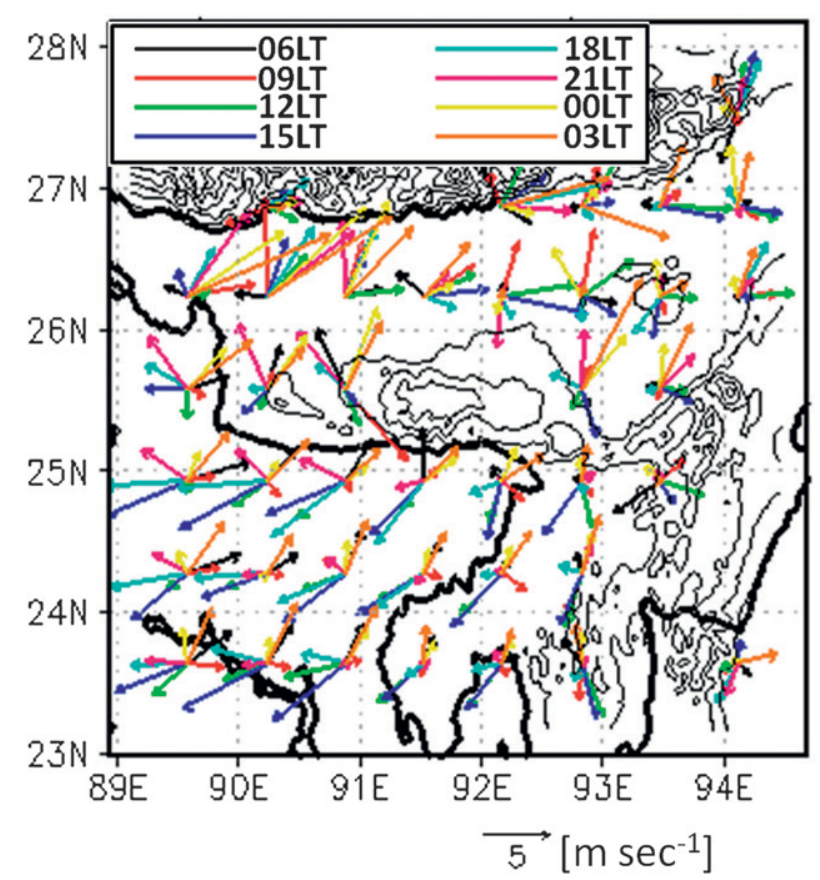

FIG. 11. Simulated diurnal variation of wind vectors $\left(\mathrm{m} \mathrm{s}^{-1}\right)$ at $900 \mathrm{hPa}$ during 6-7 Jul. Arrows indicate anomalous wind in which 2-day mean wind vectors are removed.

but the direction and wind speed is unsuitable for initiating orographic precipitation (Figs. 5 and 13). The WRF result for a typical rainfall event suggests that this is why the diurnal cycle of precipitation becomes more stimulated during the active phase.

The TRMM observation and WRF experiment reveal that the precipitation around the Meghalaya Plateau shows the prominent diurnal cycle during the active period of the submonthly ISO. During the A1 and A2 periods, westerly and southwesterly wind increases at the 850-hPa level (Figs. 4 and 5). During a typical heavy precipitation case, the LLJ over the upwind side of the mountain slope develops from midnight to early morning and initiates convective precipitation along the Meghalaya Plateau. The WRF failed to reproduce the diurnal cycle of precipitation during the $\mathrm{A} 2$ period. This could perhaps be attributed to its poorer performance for large-scale circulation after the latter part of the B1 period. In spite of exhibiting the minimum precipitation during the diurnal cycle, daytime precipitation during the active period is still higher than the daily total during the inactive period (Figs. 4 and 6). This indicates that the diurnal cycle of precipitation is not always necessary for the total rainfall amount in the active period. However, the diurnal cycle plays an important role in increasing maximum precipitation and contributing distinct differences in precipitation amount between the active and inactive periods of the submonthly ISO.

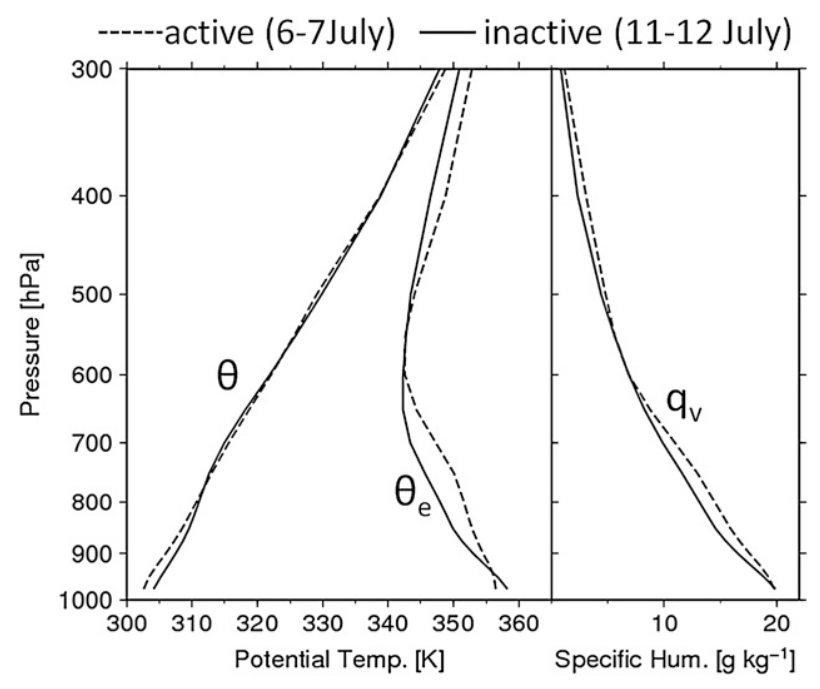

FIG. 12. Vertical profiles of potential temperature, equivalent potential temperature, specific humidity, and wind vectors over $24^{\circ}-25^{\circ} \mathrm{N}, 91^{\circ}-92^{\circ} \mathrm{E}$ during active (6-7 Jul) and inactive (11-12 Jul) periods.

\section{Discussion}

The role of the LLJ in modulating the diurnal precipitation cycle during the A1 period was addressed in section 5. Further analysis is carried out in this section to understand the differences in mesoscale properties during active and inactive periods of the submonthly ISO. We have confirmed the differences in large-scale circulation (Figs. 3 and 5) and downscaled wind pattern (Fig. 7) between active and inactive periods. It is necessary to examine atmospheric vertical profiles to investigate from a thermodynamic point of view. Vertical profiles of potential temperature and specific humidity over the Hindustan Plain are illustrated in Fig. 12. Twoday averages for 6-7 and 11-12 July, corresponding to the $\mathrm{A} 1$ and $\mathrm{B}^{\prime}$ periods, are shown. Potential temperature profiles for the two periods are very similar, except below $700 \mathrm{hPa}$. Potential temperature during this active period is larger than that in the inactive period at levels below $800 \mathrm{hPa}$. The stability is very similar for the active and inactive periods at levels below $850 \mathrm{hPa}$. However, between the 850 - and $700-\mathrm{hPa}$ levels, the active period exhibits more stable stratification. The vertical profile of specific humidity indicates that the active period is significantly wetter than the inactive period between the 600- and $975-\mathrm{hPa}$ levels. The difference in specific humidity results in higher equivalent potential temperature in the same layer during the active period. As a result, the equivalent potential temperature profile in the lower troposphere exhibits stronger convective instability in the inactive period than the active period. The vertical temperature and moisture profiles imply 


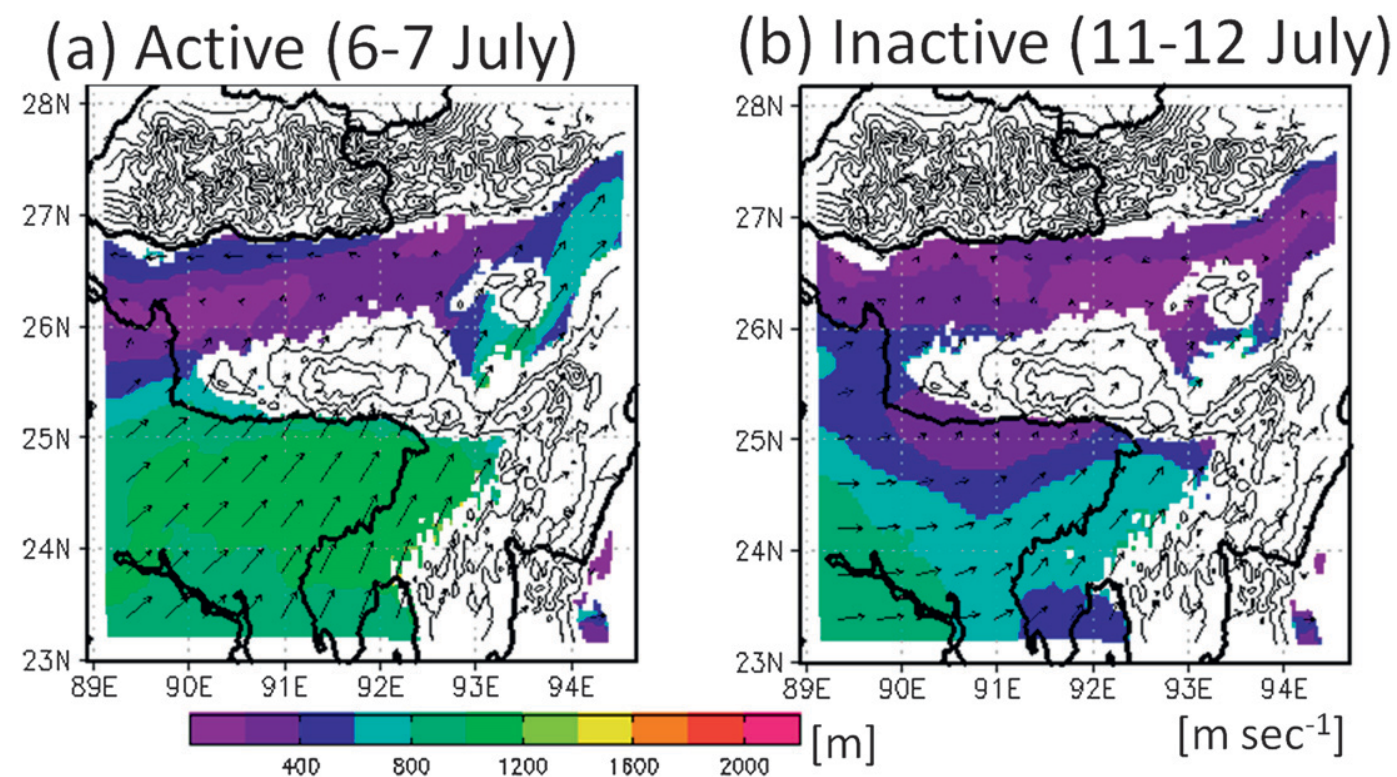

FIG. 13. Horizontal distribution of $H_{c}$ (m; shaded) and 900-hPa wind $\left(\mathrm{m} \mathrm{s}^{-1}\right)$ in WRF experiment during (a) active and (b) inactive periods.

that the inactive period more likely favors cumulus convection. However, in the active period, it is plausible that potential temperatures are subjected to vertical mixing owing to the subgrid-scale updraft/downdraft, which can make vertical stratification more stable as a consequence. We need more case studies to investigate the vertical temperature profiles in relation to the submonthly ISO.

Since the vertical temperature profile during the active period does not appear to be very unstable, a kinematic process should be crucial during the active period. Here a nondimensional Froude number (Fr) is used to describe the state of stratified flow over the obstacles, and is defined as

$$
\mathrm{Fr}=U / N H
$$

where $U$ is the wind speed, $N$ is the Brunt-Väisälä frequency, and $H$ is the height scale of the obstacle. Here Fr is defined for nonrotating flow; hence, it is applicable only for mesoscale circulations. If $\mathrm{Fr} \leq 1$, vertical stratification effects are relatively important and vertical displacement of the flow is restricted by the stratification (Cushman-Roisin 1994). Parameters are defined in consideration of the mean state of the lower troposphere; $U$ is calculated from vertical mean wind speed at $975-850 \mathrm{hPa}$, and $N$ is calculated by assuming a linear gradient of potential temperature from 975 to $850 \mathrm{hPa}$. Equation (1) is transformed as $H_{c}=U / N$ when $\mathrm{Fr} \simeq 1$. Namely, $N$ is close to the frequency of vertical displacement forced by the obstacle $(U / H)$. Then, $H_{c}$ represents the altitude that stratified flow with a speed of $U$ can attain against the stratification barrier $N$. Figure 13 depicts horizontal distribution of $H_{c}$ for active and inactive periods. To the southwest of the Meghalaya Plateau, $H_{c}$ is lower than $400 \mathrm{~m}$ during the inactive period (Fig. 13b). Conversely, $H_{c}$ is higher than $1000 \mathrm{~m}$ in the active period, indicating that the southwesterly wind is strong enough to climb the southern slope of Meghalaya. Since the lifting condensation level near the slope is below $H_{c}$ (not shown), the low-level wind around the southern slope reaches condensation level and is able to develop further with the aid of condensation heating. In contrast, southwesterly flow must pass around the plateau during the inactive period (Fig. 13b) because $H_{c}$ is lower than the Meghalaya Plateau. A remarkable difference in $H_{c}$ between the two periods is due primarily to the wind speed difference. Wind speed at $900 \mathrm{hPa}$ is more than 2 times stronger in the active period than in inactive periods (Fig. 13). Despite similar vertical stratification, there are distinct differences in low-level wind speed between the A1 and B1 periods. The stronger low-level wind during the $\mathrm{A} 1$ period can result in a larger potential for initiating cumulus convection over the mountain slope. Since the LLJ is dominant from midnight to early morning, there are more opportunities for convective initiation during this time. Furthermore, the wet lower troposphere during the active period will be an additional factor for the development of convective systems.

Recently, many studies have discussed a modulation of the diurnal cycle in relation to ISO phases, especially 
those related to the MJO, since the 30-60-day ISO and the diurnal cycle are the dominant modes in tropical regions (Yang and Slingo 2001). Rauniyar and Walsh (2011) found that the amplitude of the diurnal precipitation cycle becomes one and a half times larger than normal during the active MJO phase, although this depends on the region. The propagation of diurnal cycle signals is also influenced by the MJO; this was revealed by TRMM observations (Ichikawa and Yasunari 2008; Oh et al. 2012) and by GPS (Fujita et al. 2011) around the Maritime Continent. Oouchi et al. (2009) performed a global cloud-resolving model experiment that demonstrated that the direction of diurnal cycle propagation varies corresponding to dry/wet periods of the ISO. Conversely, the influence of the submonthly-scale ISO on the diurnal cycle of precipitation is poorly understood. Yokoi et al. (2007) found that regions of large variability in radar reflectivity for 30-60- and 10-20-day ISO modes over the Indochina Peninsula are clearly separated as a result of topographic effects because the dominant synoptic-scale winds for the two ISO modes are different that causes the orographic precipitation in the different places. Geostationary satellite data analysis suggested the prominent diurnal cycle of cloud activities during the active phase of the submonthly ISO over Bangladesh (Ohsawa et al. 2000). TRMM observations suggested that the diurnal cycle of convective activity is reinforced when the 5-20-day ISO becomes active over the Bay of Bengal (Hoyos and Webster 2007). The WRF experiment in this study revealed the influence of the submonthly-scale ISO in modulating the diurnal cycle of precipitation around the Meghalaya Plateau as a result of the intensification of the nocturnal LLJ. The nocturnal LLJ can develop even in inactive periods, but its direction and wind speed are unsuitable for initiating orographic precipitation. As mentioned in section 1, the submonthly-scale ISO in this region plays an important role in modulating interannual variability (Fujinami et al. 2011). Therefore, the diurnal cycle of precipitation is likely to have important connections with seasonal/annual mean precipitation variability. This study focuses mainly on typical rainfall events during July 2004. To understand the influence of the submonthly ISO on the diurnal cycle and role of the diurnal cycle in modulating heavy precipitation around the Meghalaya Plateau, further comprehensive studies are needed, especially those using longer numerical simulations. In addition, the number of rain gauges around the Meghalaya Plateau is obviously insufficient for the quantitative evaluation of the numerical experiment although this study used the high-resolution daily precipitation dataset. It is desirable to have more in situ observations in this region as well as the satellite remote sensing.
This study confirms that the regional atmospheric model is capable of simulating submonthly-scale ISOrelated precipitation and associated mesoscale circulations. To improve the regional model's performance in simulating mesoscale processes under large-scale atmospheric forcing, it would be necessary to reduce model biases in synoptic-scale circulation and improve the physics schemes used. In addition, the mechanism of the nocturnal LLJ in this region is an interesting topic that we have left for future studies.

\section{Conclusions}

Motivated by clarifying the mechanism responsible for the huge amount of rainfall that falls around the Meghalaya Plateau, a numerical experiment using a regional atmospheric model is conducted with $3.6-\mathrm{km}$ grid size. Since a submonthly-scale ISO is a dominant mode in precipitation variability in the region, this study focuses on June and July 2004, when a distinct 7-25-day ISO was observed. Active and inactive periods in summer 2004 are defined using the 7-25-day filtered time series of precipitation obtained from APHRODITE and TRMM observations. The lower-level circulation pattern in the reanalysis data indicates stronger westerly to southwesterly flow running toward the Meghalaya Plateau during the active period.

The WRF simulation roughly reproduced the timing and magnitude of precipitation peaks in association with the submonthly-scale ISO. However, the large-scale southwesterly wind in the B1 period is too strong, which probably results in unrealistic precipitation for the latter part of the B1 period and the A2 period. WRF tends to overestimate precipitation around the Meghalaya Plateau and Himalayas. The evaluation using TRMM Precipitation Radar indicates that WRF has the ability to simulate mesoscale convective processes during typical heavy rainfall events around the Meghalaya Plateau.

The vertical structure of simulated wind indicates a distinct nocturnal LLJ running at the 900-hPa level over the Hindustan Plain that is remarkable from 0000 to 0600 LT. The LLJ intensifies forced lifting along the southern slope of the Meghalaya Plateau and initiates developed convection there from midnight to early morning. The simulated diurnal cycle of precipitation becomes prominent during the active period of the submonthly ISO, which is in agreement with 3B42 observations. During the A1 period, the nocturnal LLJ accelerates preexisting southwesterly winds toward the southern slope of the Meghalaya Plateau and brings strong orographic precipitation. However, during the inactive period, the weaker low-level wind is insufficient to overcome the vertical stratification barrier and is 
unable to reach the lifting condensation level. Therefore, the intensity of southerly/southwesterly low-level wind is a crucial factor in heavy precipitation during the active period.

Acknowledgments. The author acknowledges the two anonymous reviewers for their useful comments, which significantly helped improve the quality of the manuscript. The author appreciates Drs. F. Murata, H. Fujinami, and T. Yasunari for their useful suggestions. This study was conducted under the support of Grant-in-Aid for Scientific Research (B-22340137) from the Japan Society for the Promotion of Sciences (JSPS), the Environment Research and Technology Development Fund [S-8-1(2)] of the Ministry of the Environment, Japan, and the Research Program on Climate Change Adaptation (RECCA) of the Ministry of Education, Culture, Sports, Science and Technology, Japan. (The APHRODITE dataset was obtained from the project website http:// www.chikyu.ac.jp/precip/.)

\section{REFERENCES}

Arakawa, O., and A. Kitoh, 2005: Rainfall diurnal variation over the Indonesian Maritime Continent simulated by $20-\mathrm{km}$ mesh GCM. SOLA, 1, 109-112.

Barros, A. P., M. Joshi, J. Putkonen, and D. W. Burbank, 2000: A study of the 1999 monsoon rainfall in a mountainous region in central Nepal using TRMM products and rain gauge observations. Geophys. Res. Lett., 27, 3683-3686.

Berbery, E. H., and J. Nogués-Paegle, 1993: Intraseasonal interactions between the tropics and extratropics in the Southern Hemisphere. J. Atmos. Sci., 50, 1950-1965.

Chen, F., and J. Dudhia, 2001: Coupling an advanced land surfacehydrology model with the Penn State-NCAR MM5 modeling system. Part I: Model description and implementation. Mon. Wea. Rev., 129, 569-585.

Cushman-Roisin, B., 1994: Introduction to Geophysical Fluid Dynamics. Prentice-Hall, 320 pp.

Dudhia, J., 1989: Numerical study of convection observed during the winter monsoon experiment using a mesoscale twodimensional model. J. Atmos. Sci., 46, 3077-3107.

Fujinami, H., and Coauthors, 2011: Characteristic intraseasonal oscillation of rainfall and its effect on interannual variability over Bangladesh during boreal summer. Int. J. Climatol., 31, 1192-1204, doi:10.1002/joc.2146.

Fujita, M., K. Yoneyama, S. Mori, T. Nasuno, and M. Satoh, 2011: Diurnal convection peaks over the eastern Indian Ocean off Sumatra during different MJO phases. J. Meteor. Soc. Japan, 89A, 317-330.

Hendon, H. H., and M. L. Salby, 1994: The life cycle of the MaddenJulian oscillation. J. Atmos. Sci., 51, 2225-2237.

Hirose, M., and K. Nakamura, 2005: Spatial and diurnal variation of precipitation systems over Asia observed by the TRMM precipitation radar. J. Geophys. Res., 110, D5106, doi:10.1029/ 2004JD004815.

Hong, S.-Y., J. Dudhia, and S.-H. Chen, 2004: A revised approach to ice microphysical processes for the bulk parameterization of clouds and precipitation. Mon. Wea. Rev., 132, 103-120.
Hoyos, C. D., and P. Webster, 2007: The role of intraseasonal variability in the nature of Asian monsoon precipitation. J. Climate, 20, 4402-4424.

Huang, H.-L., C. C. Wang, G. T. J. Chen, and R. E. Carbone, 2010: The role of diurnal solenoidal circulation on propagating rainfall episodes near the eastern Tibetan Plateau. Mon. Wea. Rev., 138, 2975-2989.

Ichikawa, H., and T. Yasunari, 2008: Intraseasonal variability in diurnal rainfall over New Guinea and the surrounding oceans during austral summer. J. Climate, 21, 2852-2868.

Kain, J. S., 2004: The Kain-Fritsch convective parameterization: An update. J. Appl. Meteor., 43, 170-181.

Kanamitsu, M., W. Ebisuzaki, J. Woollen, S.-K. Yang, J. J. Hnilo, M. Fiorino, and G. L. Potter, 2002: NCEP-DOE AMIP-II Reanalysis (R-2). Bull. Amer. Meteor. Soc., 83, 1631-1643.

Kataoka, A., and T. Satomura, 2005: Numerical simulation on the diurnal variation of precipitation over northeastern Bangladesh: A case study of an active period 14-21 June 1995. SOLA, 1, 205-208.

Krishnamurti, T. N., and H. N. Bhalme, 1976: Oscillations of a monsoon system. Part I: Observational aspects. J. Atmos. Sci., 33, 1937-1954.

Leduc, M., and R. Laprise, 2009: Regional climate model sensitivity to domain size. Climate Dyn., 32, 833-854.

Madden, R. A., and P. R. Julian, 1972: Description of global-scale circulation cells in the tropics with a $40-50$ day period. J. Atmos. Sci., 29, 1109-1123.

Miura, H., M. Satoh, T. Nasuno, A. T. Noda, and K. Oouchi, 2007: A Madden-Julian oscillation event simulated using a global cloud-resolving model. Science, 318, 1763-1765.

Mlawer, E. J., S. J. Taubman, P. D. Brown, M. J. Iacono, and S. A. Clough, 1997: Radiative transfer for inhomogeneous atmosphere: RRTM, a validated correlated-k model for the longwave. J. Geophys. Res., 102 (D14), 16 663-16 682.

Mori, S., and Coauthors, 2004: Diurnal land-sea rainfall peak migration over Sumatera Island, Indonesian maritime continent, observed by TRMM satellite and intensive rawinsonde soundings. Mon. Wea. Rev., 132, 2021-2039.

Murakami, M., 1976: Analysis of summer monsoon fluctuations over India. J. Meteor. Soc. Japan, 54, 15-31.

Murata, F., T. Terao, T. Hayashi, H. Asada, and J. Matsumoto, 2008: Relationship between atmospheric conditions at Dhaka, Bangladesh, and rainfall at Cherrapunjee, India. Nat. Hazards, 44, 399-410, doi:10.1007/s11069-007-9125-2.

Nakanishi, M., and H. Niino, 2004: An improved Mellor-Yamada level-3 model: Its design and verification. Bound.-Layer Meteor., 112, 1-31.

$\longrightarrow$, and — 2006: An improved Mellor-Yamada level-3 model: Its numerical stability and application to a regional prediction of advection fog. Bound.-Layer Meteor., 119, 397-407.

Nesbitt, S. W., and E. J. Zipser, 2003: The diurnal cycle of rainfall and convective intensity according to three years of TRMM measurements. J. Climate, 16, 1456-1475.

Oh, J. H., K.-Y. Kim, and G.-H. Lim, 2012: Impact of MJO on the diurnal cycle of rainfall over the western Maritime Continent in the austral summer. Climate Dyn., 38, 1167-1180.

Ohsawa, T., T. Hayashi, Y. Mitsuta, and J. Matsumoto, 2000: Intraseasonal variation of monsoon activities associated with the rainfall over Bangladesh during the 1995 summer monsoon season. J. Geophys. Res., 105 (D24), 29 445-29 459.

- H. Heda, T. Hayashi, A. Watanabe, and J. Matsumoto, 2001: Diurnal variations of connective activity and rainfall in tropical Asia. J. Meteor. Soc. Japan, 79, 333-352. 
Oouchi, K., A. T. Noda, M. Satoh, B. Wang, S.-P. Xie, H. G. Takahashi, and T. Yasunari, 2009: Asian summer monsoon simulated by a global cloud-system-resolving model: Diurnal to intra-seasonal variability. Geophys. Res. Lett., 36, L11815, doi:10.1029/2009GL038271.

Rauniyar, S. P., and K. J. E. Walsh, 2011: Scale interaction of the diurnal cycle of rainfall over the Maritime Continent and Australia: Influence of the MJO. J. Climate, 24, 325-348.

Reynolds, R. W., N. A. Rayner, T. M. Smith, D. C. Stokes, and W. Wang, 2002: An improved in situ and satellite SST analysis for climate. J. Climate, 15, 1609-1625.

Romatschke, U., and R. A. Houze Jr., 2011: Characteristics of precipitation convective systems in the South Asian monsoon. J. Hydrometeor., 12, 3-26.

Sardeshmukh, P. D., and B. J. Hoskins, 1988: The generation of global rotational flow by steady idealized tropical divergence. J. Atmos. Sci., 45, 1228-1251.

Sato, T., and Y. Xue, 2013: Validating regional climate model's downscaling ability for East Asian summer monsoon's interannual variability. Climate Dyn., doi:10.1007/s00382-012-1616-5, in press.

- H. Miura, and M. Satoh, 2007: Spring diurnal cycle of clouds over Tibetan Plateau: Global cloud-resolving simulations and satellite observations. Geophys. Res. Lett., 34, L18816, doi:10.1029/2007GL030782.

,,,--- Y. N. Takayabu, and Y. Wang, 2009: Diurnal cycle of precipitation in the tropics simulated in a global cloudresolving model. J. Climate, 22, 4809-4826.

Skamarock, W. C., and Coauthors, 2008: A description of the Advanced Research WRF version 3. NCAR Tech. Note NCAR/TN-475+STR, 113 pp. [Available online at http:// www.mmm.ucar.edu/wrf/users/docs/arw_v3_bw.pdf.]

Terao, T., Md. N. Islam, T. Hayashi, and T. Oka, 2006: Nocturnal jet and its effects on early morning rainfall peak over northeastern Bangladesh during the summer monsoon season. Geophys. Res. Lett., 33, L18806, doi:10.1029/2006GL026156.
Waliser, D. E., W. Stern, S. Schubert, and K. M. Lau, 2003: Dynamic predictability of intraseasonal variability associated with the Asian summer monsoon. Quart. J. Roy. Meteor. Soc., 129, 2897-2925.

Wang, Y., L. R. Leung, J. L. McGregor, D. K. Lee, W. C. Wang, Y. Ding, and F. Kimura, 2004: Regional climate modeling: Progress, challenges, and prospects. J. Meteor. Soc. Japan, 82 , 1599-1628.

Webster, P. J., and Coauthors, 2002: The JASMINE pilot study. Bull. Amer. Meteor. Soc., 83, 1603-1630.

Wheeler, M., and K. M. Weickmann, 2001: Real-time monitoring and prediction of modes of coherent synoptic to intraseasonal tropical variability. Mon. Wea. Rev., 129, 2677-2694.

Xu, W., and E. Zipser, 2011: Diurnal variations of precipitation, deep convection, and lightning over and east of the eastern Tibetan Plateau. J. Climate, 24, 448-465.

Yang, G.-Y., and J. Slingo, 2001: The diurnal cycle in the tropics. Mon. Wea. Rev., 129, 784-801.

Yasunari, T., 1979: Cloudiness fluctuations associated with the Northern Hemisphere summer monsoon. J. Meteor. Soc. Japan, 57, 227-242.

Yatagai, A., O. Arakawa, K. Kamiguchi, H. Kawamoto, M. I. Nodzu, and A. Hamada, 2009: A 44-year daily gridded precipitation dataset for Asia based on a dense network of rain gauges. SOLA, 5, 137-140.

— , K. Kamiguchi, O. Arakawa, A. Hamada, N. Yasutomi, and A. Kitoh, 2012: APHRODITE: Constructing a long-term daily gridded precipitation dataset for Asia based on a dense network of rain gauges. Bull. Amer. Meteor. Soc., 93, 1401-1415.

Yokoi, S., T. Satomura, and J. Matsumoto, 2007: Climatological characteristics of the intraseasonal variation of precipitation over the Indochina Peninsula. J. Climate, 20, 5301-5315.

Zhou, T., R. Yu, H. Chen, A. Dai, and Y. Pan, 2008: Summer precipitation frequency, intensity, and diurnal cycle over China: A comparison of satellite data with rain gauge observations. J. Climate, 21, 3997-4010. 